\title{
Application of Locking Compression Plate as Hybrid Locked Plate for Transverse and Short Oblique Diaphyseal Fractures of Tibia and Radius-Ulna in Dogs
}

\author{
Surendra Dunthur Siddaraju, Aswathy Gopinathan*, Kiranjeet Singh, Sherin B. Sarangom and \\ Sowbharenya Chelladurai
}

Division of Surgery, ICAR-IVRI, Izatnagar, Bareilly (U.P.) Uttar Pradesh, INDIA

*Corresponding author: A Gopinathan; E-mail: aswathykiran77@gmail.com

Received: 28 July, 2021

Revised: 22 Aug., 2021

Accepted: 01 Sept., 2021

\begin{abstract}
Study was conducted to evaluate clinical effect of hybrid locked plating for management of transverse and short oblique diaphyseal fracture of tibia and radius-ulna in 12 dogs. Based on demographic data, clinical and radiographic evaluation, preoperative planning was done. Stable fixation was achieved with locking plates (2.7 or $3.5 \mathrm{~mm}$ ) in hybrid locking manner. Stance, gait, pain and lameness were scored and evaluated at regular intervals which showed improvement over time. Complete weight bearing was observed in all cases with no observable lameness on $10^{\text {th }}$ postoperative week. Primary bone healing was initiated on $6^{\text {th }}$ postoperative week in $83.3 \%$ of cases and complete cortical continuity was noticed on $10^{\text {th }}$ week post-surgery. Seroma, wound dehiscence and screw loosening were some of the minor complications observed and outward limb rotation was observed due to anatomical mal-alignment. Functional recovery was good in $83.3 \%$ of the cases. Technique of hybrid locked plating provided effective inter-fragmentary compression and achieved complete radiographic primary union with very good functional outcome when applied on transverse and short oblique diaphyseal fracture of tibia and radius-ulna in dogs.
\end{abstract}

\section{HIGHLIGHTS}

( Application of Locking Compression Plate as Hybrid Locked Plate provided effective inter-fragmentary compression and achieved complete radiographic primary union with very good functional outcome when applied on transverse and short oblique diaphyseal fracture of tibia and radius-ulna in dogs

Keywords: Hybrid locked plate, Diaphyseal fracture, Tibia, Radius-ulna, Dogs

A versatile use of locking technology for successful fracture fixation is Hybrid locked plating wherein both locking and non-locking screws are used with a pre contoured locking plate construct (Johnson, 2013). Non locking screw and contoured plate brings about inter-fragmentary compression, either as an inter-fragmentary screw through the plate or as in dynamic compression plating, in reduced fracture fragments. Hybrid locked plating technique provides better torsional and bending resistance than a construct with locking screws only (Bel 2018). Anchoring of threaded holes of locking plate to threaded screws allows angular and axial stability to screws relative to the plate (Au et al., 2017). Experimental studies support their use in osteopenic bone fractures with minimum deviation in anatomic alignment, in situations wherein exact plate contouring is difficult or where standard bicortical screws were unable to gain sufficient purchase for maintenance of the plate-bone relationship (Scolaro and Ahn, 2011). Biomechanical and controlled experimental studies on hybrid locked plating using bone analogues (Wynkoop et al., 2017); and in clinical cases (Gibert et al., 2015) were conducted with positive results. Clinical studies on

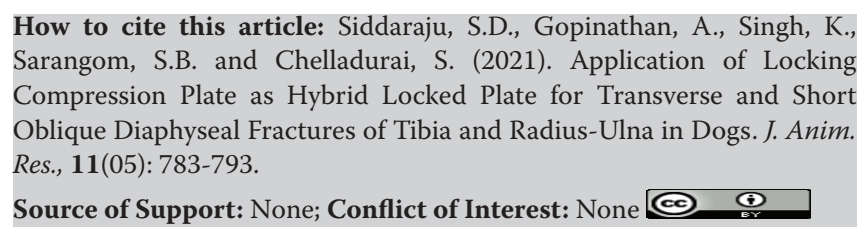


hybrid locked plating technique in dogs are few hence this study was undertaken to generate firsthand information on the applicability of the same in clinical cases for the management of transverse and short oblique diaphyseal fracture of tibia and radius-ulna in dogs.

\section{MATERIALS AND METHODS}

This study was conducted on 12 client owned dogs with simple transverse and short oblique fracture of tibia and radius-ulna presented to Referral veterinary polyclinic, Indian Veterinary Research Institute, India. Data regarding the signalments (age, breed, and body weight), general body condition, fracture etiology, time lapsed after injury, earlier treatments given, and extent of soft tissue injury were recorded. Unger's guidelines with alphanumeric code were employed to classify fracture type after evaluating radiographs taken in two orthogonal views. Soft tissue inflammation, posture, and lameness were evaluated and scores were assigned preoperatively and surgery was planned based on clinical and radiographic evaluation. Locking plates $(2.7 \& 3.5 \mathrm{~mm})$ and locking screws with threaded head manufactured from 316L stainless steel metal alloy marketed by NEBULA (NEBULA Surgical Pvt. Ltd., Rajkot, Gujarat, India) were used in all cases.

All dogs were injected with atropine sulphate (Atropine sulphate, Hindustan pharmaceuticals, Barauni, India) at a dose rate of $0.04 \mathrm{mg} / \mathrm{kg}$ bodyweight IM followed by intravenous infusion of butorphanol (Butrum-1, Aristo Pharmaceuticals Pvt. Ltd., Raisen, India) at a dose rate of $0.05 \mathrm{mg} / \mathrm{kg}$ bodyweight and diazepam (Calmpose, Ranbaxy Laboratory limited, Baddi, Himachal Pradesh, India) at a dose rate of 0.5 milligram per $\mathrm{kg}$ body weight consecutively after an interval of 5 minutes between injections. Anesthetic induction was done by intravenous administration of $1 \%$ propofol (Neorof, Neon Laboratories Limited, Mumbai, India) 'till effect' 5 minutes after administration of pre- anesthetics. Anesthesia was maintained with Isoflurane 2\% (Sosrane, Neon Laboratories Limited, Mumbai, India) at oxygen flow rate of $100-200 \mathrm{ml} / \mathrm{kg} /$ minute.

Diaphysis of tibia was approached cranio-medially while cranio-lateral approach employed for diaphysis of radius-ulna (Johnson, 2013). Dogs were kept in lateral recumbency with the affected tibia kept downwards close to surgical table while in radius-ulna fracture, concerned limb was placed up and free to be handled by surgeon. Strict aseptic measures were followed throughout scrubbing and draping before skin incision. Extensors and flexors up to their tendinous insertions were retracted to expose the diaphysis of radius and tibia. Care was taken to preserve the cephalic vein on the cranio-lateral aspect of radius-ulna and the saphenous vein and nerve on the medial aspect of tibia. Size and length of locking plates (NEBULA) were determined based on bone size, length and body weight of dogs. The locking plates were placed over the anatomically reduced fracture fragments on medial side of tibia and cranial side of radius and leaving one or two holes over fracture, a non-locking cortical screw was placed in neutral position on the distal fracture fragment followed by another screw on the proximal fragment; loaded eccentrically in the pre-tapped drill hole in dynamic compression unit (DCU) of locking plate, to achieve inter-fragmentary compression of fracture fragments. Self-tapping locking head screws were placed in rest of the holes, in far-near-near-far fashion at neutral position, drilled through a locking drill sleeve with appropriate size drill bits as per AO guidelines (Fig. 1A and 1B). Muscle, fascia and skin incision were sutured as per standard protocol. Extent of manipulation and soft tissue damage, ease/ difficulty faced by surgeon technique-wise, intraoperative stability, complications (if any), and duration of surgery were recorded. Intra-operative soft tissue damage was scored as 1: severe trauma/tear on surrounding soft tissues, 2: moderate trauma/tear on surrounding soft tissues, 3: mild trauma/tear on surrounding soft tissues and 4: soft tissues intact, without any damage.

Postoperatively all dogs received antibiotic ceftriaxone sodium (Intacef, Intas Pharmaceuticals Limited, Ahmadabad, India) and meloxicam (Melonex, Intas Pharmaceuticals Limited, Ahmadabad, India) for a week. Surgical wound was cleaned daily with povidone-iodine $(5 \% \mathrm{w} / \mathrm{v})$ and soft bandage was applied over the limb till suture removal on the $10^{\text {th }}$ postoperative day. Weight bearing limited to walking was advised for first 2 weeks.

Surgical wound healing was evaluated on $10-14^{\text {th }}$ postoperative day and was graded as satisfactory or not. Postoperative evaluation of pain (Cross et al., 1997), posture, lameness (Cook et al., 1999) and radiographic healing were made on $6^{\text {th }}$ and $10^{\text {th }}$ postoperative week and were given scores. Post-operative pain was graded as: 1 (severe-animal not allowing manipulation of limb), 


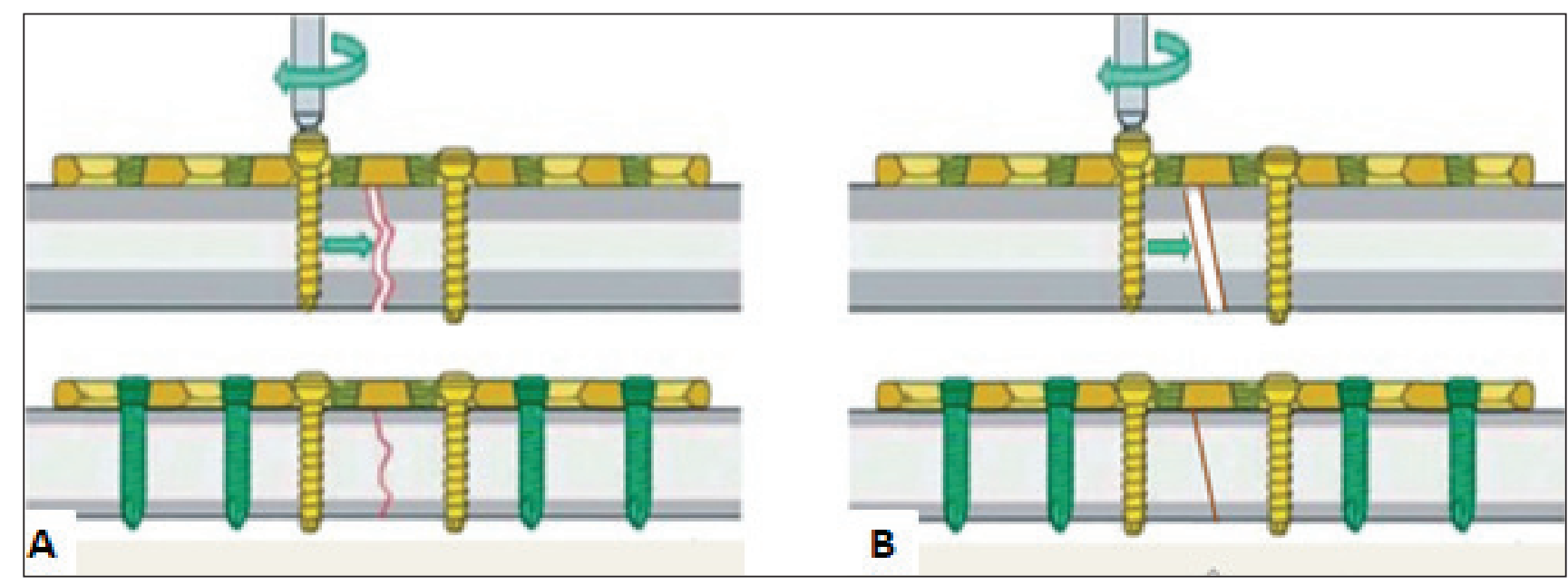

Fig. 1: Plate osteosynthesis in hybrid locking mode for transverse (A) and short oblique (B) diaphyseal fracture of tibia and radiusulna

2 (moderate- animal will not allow manipulation through normal range of motion; acknowledges pain), 3 (mildanimal allows manipulation of limb through normal range of motion, but acknowledges pain by turning head or pulling away) and 4 (no pain response on manipulation of limb). Lameness score was assigned as: 1 (non-weight bearing lameness); 2 (severe weight bearing lameness "toe-touching" only); 3 (moderate weight bearing lameness, obvious lameness with noticeable "head-bob" and change in gait); 4 (consistent mild weight bearing lameness with little change in gait); 5 (intermittent mild weight bearing lameness with little if any change in gait); 6 (no observable lameness).

Orthogonal cranio-caudal and medio-lateral radiographs of the operated limb were evaluated to assess the alignment of the bone, apposition of the fragments, configuration and status ofimplant, stage of fracture healing and complications if any. A scoring system for fracture healing under compression was used to assess the radiographic healing pattern of simple fracture managed by compression using locking plate (Sirin et al., 2018). Radiographic appearance of fracture site was scored as: 1 (Presence of fracture line with sharp fracture edges); 2 (Presence fracture line with haziness at the fracture edges); 3 (Faintly visible fracture edges with cortical continuity); 4 (Obliteration of fracture line with complete cortical continuity). Callus formation (if any) after complete radiographic healing was scored as: 1 (Cortical continuity with severe callus); 2 (Cortical continuity with moderate callus); 3 (Cortical continuity with mild callus); 4 (Cortical continuity with minimum callus). Complications of fracture healing (if any) observed during postoperative follow-up were graded as minor and major (Dvorak et al., 2000). Slight mal-alignment, slight or partial loosening of implants, mild arthrosis in the surrounding joints, hypertrophic callus, and delayed union of the fracture were considered as minor complications whereas major complications included severe malalignment, severe arthrosis on the surrounding joints, nonunion, osteomyelitis, muscle contractures and implant failure. On the basis of lameness score and radiographic bone union, functional recovery was evaluated and graded on $10^{\text {th }}$ postoperative week (Kumar, 2007). The functional recovery of the repair was scored as: 'very good' (fracture healed with normal leg usage); 'good' (fracture healed with persisted slight lameness); 'satisfactory' (Delayed union with apparent lameness); and 'unsatisfactory' (fracture failed to heal due to fixation failure or infection).

The data was statistically analyzed using SPSS software version 22.0 (SPSS, Inc., Chicago, IL). The parametric variables and nonparametric variables were expressed as Mean $\pm \mathrm{SE}$, median $\pm \mathrm{SE}$ and range, respectively. Independent samples " $t$ " test was used to compare the parametric data at different time intervals post fixation. Wilcoxon Signed Ranks Test was used for non-parametric data to check significant difference $(p<0.05)$ between follow-up intervals.

\section{RESULTS AND DISCUSSION}


Nine male dogs and three females included in this study were of average age of $29.16 \pm 5.75$ months (mean $\pm \mathrm{SE}$ ) (range: 8-60 months) and average body weight of 15.0 $\pm 0.99 \mathrm{~kg}$ (Mean $\pm \mathrm{SE}$ ) (range: 11-22 kg). Breed wise there were non-descript $\operatorname{dogs}(\mathrm{n}=5)$, Indian Spitz $(\mathrm{n}=3)$, Labrador retriever (2), American Pit Bull Terrier $(\mathrm{n}=1)$ and Boxer $(\mathrm{n}=1)$. Road accident was the most common etiological factor $(\mathrm{n}=8)$, following fall from a height $(\mathrm{n}=2)$ and $\operatorname{dog}$ fight $(\mathrm{n}=2)$. The mean time lapsed till clinical presentation after fracture occurrence was $4.33 \pm 1.59$ days (Mean \pm SE) (range 1-20 days). Preoperative soft tissue inflammation, edema and pain were mild in seven cases and moderate in others. Seven dogs were carrying their limb off the ground and five were touching only the toe on the ground when presented to clinics with fracture. Severe grade of lameness was seen three cases, moderate lameness in four and five dogs experienced non-weight bearing lameness. Unger's classification of fracture type revealed six cases were of simple short oblique fracture and others were transverse fractures. None of the cases showed neuromuscular/soft tissue injury associated with fracture. Pre-operative soft tissue inflammation, posture, and lameness scores on the day of presentation are summarized in Table 1.
Study included small to medium sized, young adult to mature adult dogs. Road accident was the most common cause of fracture, predominantly in male dogs. Preference for male is more in urban society. Fracture cases were reported sooner in majority of the cases because of awareness among the pet owners about the welfare of the animals. Fractures were mostly seen at the mid-diaphysis in both tibia and radius-ulna. Many researchers have recorded higher percentage of fractures in middle third followed by proximal third of tibia (Singh et al., 1983) and distal third of radius-ulna (Thilagar and Balasubramanian, 1988).

Mild soft tissue damage was seen in seven and moderate soft tissue damage was seen in five cases intra-operatively. Fragments were easily reduced in eight cases while fracture fragment reduction was moderately difficult in four cases, which necessitated additional surgical exposure, toggling of fracture, and application of ancillary devices (lag screw in A-1 and circlage wiring A-2 and A-3). Prefracture configurations of bones could be established before hybrid locked plating. Locking compression plate of appropriate size was chosen as per bodyweight and the fracture configuration. Fixation was achieved with $2.7 \mathrm{~mm}$

Table 1: The details of case included in study on the day of presentation

\begin{tabular}{llllllllll}
\hline $\begin{array}{l}\text { Case } \\
\text { no }\end{array}$ & Breed & $\begin{array}{l}\text { Age } \\
\text { (months) }\end{array}$ & Sex & $\begin{array}{l}\text { Body weight } \\
\text { (Kg) }\end{array}$ & Etiology & $\begin{array}{l}\text { Bone } \\
\text { Involved }\end{array}$ & $\begin{array}{l}\text { Side } \\
\text { affected }\end{array}$ & $\begin{array}{l}\text { Time lapse in } \\
\text { presentation } \\
\text { (days) }\end{array}$ & $\begin{array}{l}\text { Configuration of } \\
\text { simple, diaphyseal } \\
\text { fracture }\end{array}$ \\
\hline 1 & Labrador R. & 12 & F & 14 & DF & T & L & 1 & Short oblique \\
2 & Indian spitz & 60 & F & 12 & DF & T & L & 2 & Short oblique \\
3 & Pitbull terrier & 8 & M & 18 & RTA & T & L & 3 & Short oblique \\
4 & Non- descript & 60 & M & 11 & RTA & T & R & 3 & Transverse \\
5 & Labrador R. & 14 & M & 16 & RTA & T & L & 2 & Transverse \\
6 & Non- descript & 18 & M & 18 & RTA & T & R & 1 & Transverse \\
7 & Indian spitz & 18 & M & 12 & FFH & R-U & L & 20 & Short oblique \\
8 & Non- descript & 48 & F & 14 & RTA & R-U & R & 10 & Short oblique \\
9 & Non- descript & 48 & M & 11 & RTA & R-U & R & 1 & Transverse \\
10 & Indian spitz & 36 & M & 14 & FFH & R-U & R & 2 & Transverse \\
11 & Non-descript & 18 & M & 18 & RTA & R-U & R & 5 & Short oblique \\
12 & Boxer & 10 & M & 22 & RTA & R-U & R & 2 & Transverse \\
\hline Mean & S SE & $29.16 \pm 5.75$ & - & $15.0 \pm 0.99$ & - & - & - & $4.33 \pm 1.59$ & - \\
\hline
\end{tabular}

F- Female; M-Male; DF-Dog fight; RTA-Road traffic accident; FFH- Fall from height) (T- Tibia; R-U- Radius-ulna; L-Left; R- Right). 
plate in four cases and $3.5 \mathrm{~mm}$ plate in remaining cases. Curvature of the radius/ulna and tibia necessitated plate contouring. Intra-operative stability of fracture fragments was good and hybrid locked plating technique offered fragment stability and good anatomical alignment. Mean time required for surgery was $58 \pm 2.44$ minutes which was relatively a lower duration compared to other fixation techniques as cited in the literature; average 75 minutes for LCP fixation (Ramesh, 2011), 157 minutes for plate-rod fixation (Reems et al., 2003) and 96 minutes for external skeletal fixation (Johnson et al., 1996). Fracture type and their location were also considered while calculating mean duration of surgery. Intra-operative observations are presented in Table 2 .

Table 2: The details of intra-operative observations recorded in each case

\begin{tabular}{llllll}
\hline $\begin{array}{l}\text { Case } \\
\text { no }\end{array}$ & $\begin{array}{l}\text { Unger's } \\
\text { class }\end{array}$ & $\begin{array}{l}\text { Reduction } \\
\text { ease }\end{array}$ & $\begin{array}{l}\text { Size of } \\
\text { plate used } \\
(\mathbf{m m})\end{array}$ & $\begin{array}{l}\text { Ancillary } \\
\text { technique } \\
\text { used }\end{array}$ & $\begin{array}{l}\text { Stability } \\
\text { of implant }\end{array}$ \\
\hline 1 & $42 \mathrm{~A} 2$ & Moderate & 3.5 & Lag screw & Good \\
2 & $42 \mathrm{~A} 2$ & Easy & 2.7 & Cerclage wire Good \\
3 & $42 \mathrm{~A} 2$ & Easy & 3.5 & Cerclage wire Good \\
4 & $42 \mathrm{~A} 3$ & Easy & 2.7 & None & Good \\
5 & $42 \mathrm{~A} 3$ & Easy & 3.5 & None & Good \\
6 & $42 \mathrm{~A} 3$ & Easy & 2.7 & None & Good \\
7 & $22 \mathrm{~A} 2$ & Moderate & 3.5 & None & Good \\
8 & $22 \mathrm{~A} 2$ & Moderate & 2.7 & None & Good \\
9 & $22 \mathrm{~A} 3$ & Easy & 3.5 & None & Good \\
10 & $22 \mathrm{~A} 3$ & Easy & 3.5 & None & Good \\
11 & $22 \mathrm{~A} 2$ & Easy & 3.5 & None & Good \\
12 & $22 \mathrm{~A} 3$ & Easy & 3.5 & None & Good \\
\hline
\end{tabular}

Plate was selected based on body weight and length of bone (Reems et al., 2003). LCP has higher profile and a larger width and thickness in comparison to standard DCP (Namazi and Mozaffarian, 2007). This was a critical factor for distal limb fracture fixation especially for breeds with slender muscle coverage over their lower limbs such as Indian Spitz and Non-descript dogs, wherein high profile of plated posed problems on closure of muscle and skin. Intra-operative soft tissue damage reflected the preoperative inflammation and edema due to fracture forces.

Although exact adaptation of the locking plate to the bone surface is not necessary, pre-contouring of the plate to the bone was done to reduce gap between bone plate interface and aid hybrid locked plating (Niemeyer and Sudkamp, 2006). This ensures less stress on the soft tissue especially in the distal fragment, allows poly-axial anchorage of screws and offers increased resistance to screw pullout (Niemeyer and Sudkamp, 2006). Attention was paid while screw placement and tightening of screws especially of LHS as they don't provide sufficient tactile feedback of complete tightening of the screw (Kallianpur et al., 2018). Mean time required for surgery was $58 \pm 2.44$ minutes which was relatively a lower duration compared to other fixation techniques as cited in the literature; average 75 minutes for LCP fixation (Ramesh, 2011), 157 minutes for plate-rod fixation (Reems et al., 2003) and 96 minutes for external skeletal fixation (Johnson et al., 1996). Fracture type and their location were also considered while calculating mean duration of surgery.

Surgical incision healed uneventfully by 2 weeks and in one case, second intention healing was observed upto $7^{\text {th }}$ week. Weight bearing on the operated limb was observed on $2^{\text {nd }}$ week post-operatively. There was pain on palpation and manipulation of affected limb till $1^{\text {st }}$ week post-surgery which gradually decreased till $6^{\text {th }}$ postoperative week (Fig. $2,3,4$ and 5). On $6^{\text {th }}$ week, lameness score was 1 in 5 cases, score 2 in 3 cases and score 3 in 4 cases and pain score was 1 in 10 cases and 2 in 2 cases. Pain and inflammation associated with fracture fixation led to varying degree of lameness at immediate postoperative period. Gradual improvement in weight bearing was noticed over the follow up visits due to pain amelioration and stability of fracture fixation. Researchers opined that return of limb function and weight bearing in the initial period could be due to the stability provided by the repair and the minimal soft tissue trauma at the surgical site (Moses et al., 2002). Complete weight bearing was observed in most of the animals on $6^{\text {th }}$ postoperative week indicating that peak stages of bone union with stable screw-implant constructs allowed loading of weight. As fracture healing progresses, weight bearing improves while stable implant aids fracture healing and weight loading (Perren, 2002). Early Weight bearing on the day of suture removal after locking plate fixation in 20 cases of distal radius-ulna fracture of toy and miniature dog breeds was reported (Gibert et al., 2015). Though early weight bearing on the fractured limb was observed after hybrid locked plating, lameness evaluation 


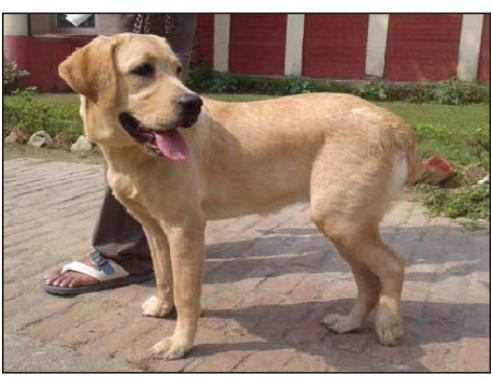

(a)

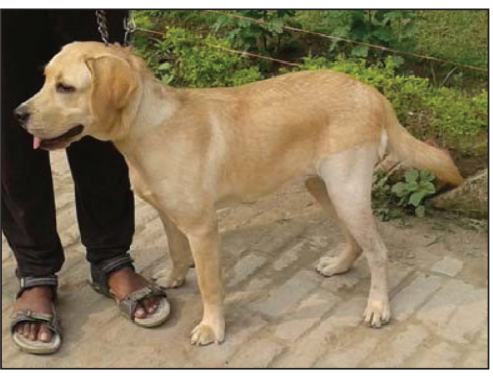

(b)

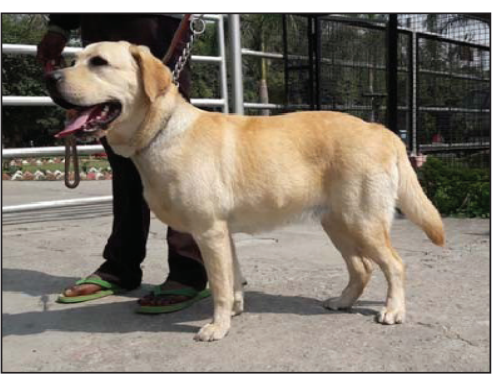

(c)

Fig. 2: Photographs of animal (Case-1) showing weight bearing while standing on preoperative $(\mathbf{a}), 6^{\text {th }}(\mathbf{b})$ and $10^{\text {th }}(\mathbf{c})$ postoperative week

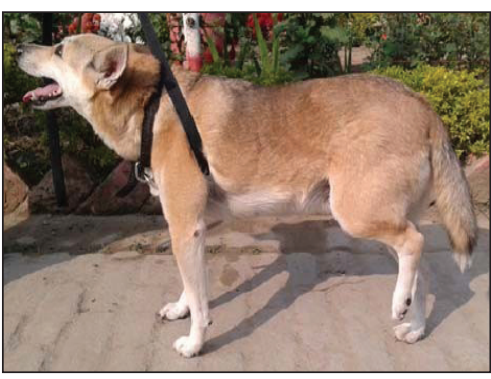

(a)

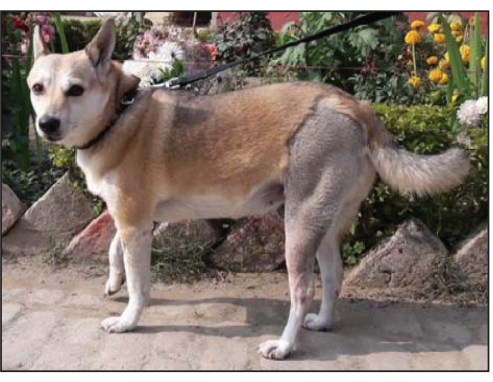

(b)

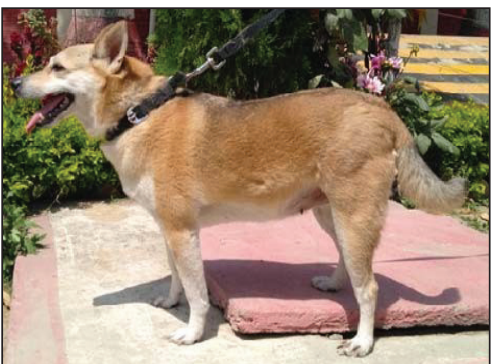

(c)

Fig. 3: Photographs of animal (Case-2) showing weight bearing while standing on preoperative (a), $6^{\text {th }}(\mathbf{b})$ and $10^{\text {th }}(\mathbf{c})$ postoperative week

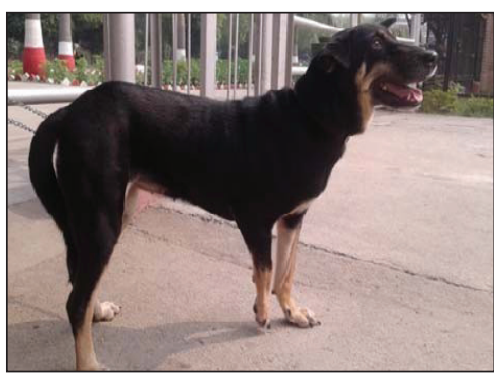

(a)

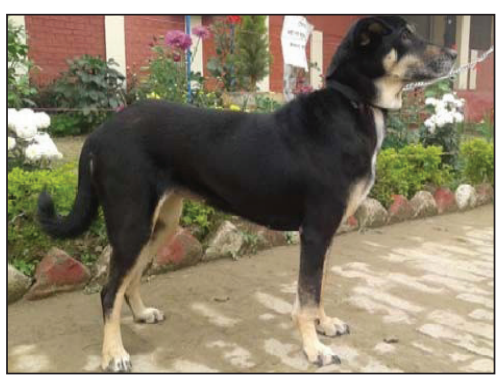

(b)

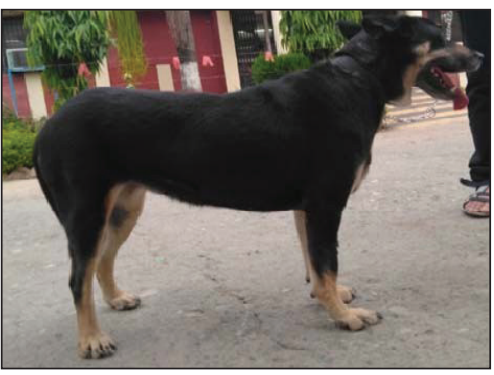

(c)

Fig. 4: Photographs of animal (Case-8) showing weight bearing while standing on preoperative $(\mathbf{a}), 6^{\text {th }}(\mathbf{b})$ and $10^{\text {th }}(\mathbf{c})$ postoperative week

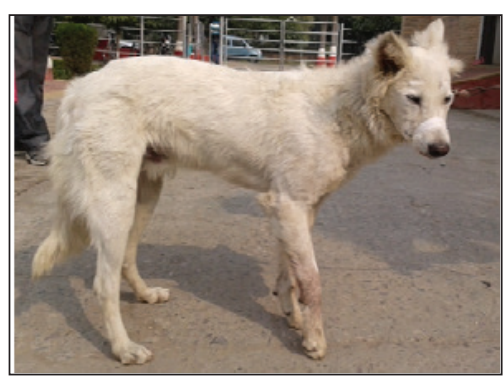

(a)

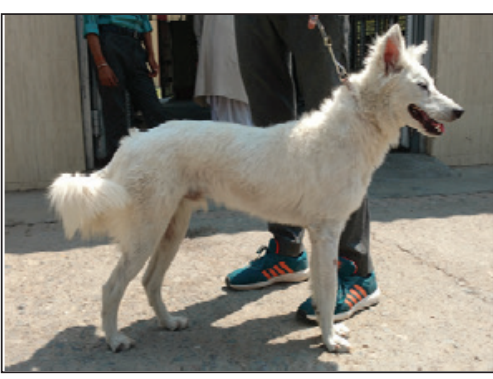

(b)

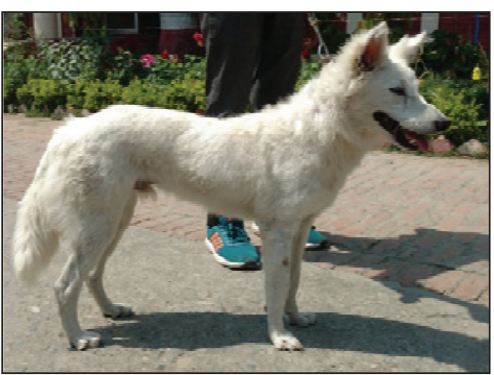

(c)

Fig. 5: Photographs of animal B-4 showing weight bearing while standing on preoperative $(\mathbf{a}), 6^{\text {th }}(\mathbf{b})$ and $10^{\text {th }}(\mathbf{c})$ postoperative week 
was not attempted at initial postoperative period to limit its adverse effect on stability of fixation and fracture healing (Kallianpur et al., 2018).

Radiographic primary bone union was observed in 10 cases (score 3) where fixation maintained stable reduction and alignment (Fig. 6, 7, 8 and 9). Loss of alignment was observed in 2 cases due to excessive movement of the limb post-fracture fixation where fracture fragments were connected through moderate amount of bridging callus. Except one, all eleven cases showed lameness score 6 and pain score 4 on $10^{\text {th }}$ postoperative week. Complete cortical continuity with obliteration of fracture line (score 4) was evident in 10 cases (Fig. 5, 6, 7 and 8). Fracture was healed by callus formation in 2 cases. Amount of callus formed on $10^{\text {th }}$ postoperative week was scored 2 in one case and scored 3 in another case. Iatrogenic ulna defect was persisted as nonunion in one, but stability of the fixation and bone healing pattern of radius was not affected. Postoperative scores for pain, posture, and lameness improved significantly $(\mathrm{p}<0.05)$ by end of follow up period.

In the present study, fracture healed by primary contact

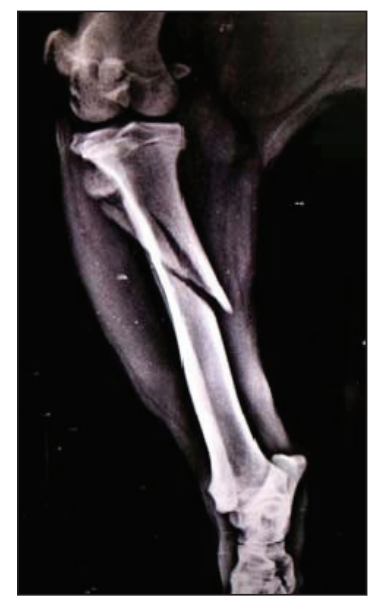

(a)

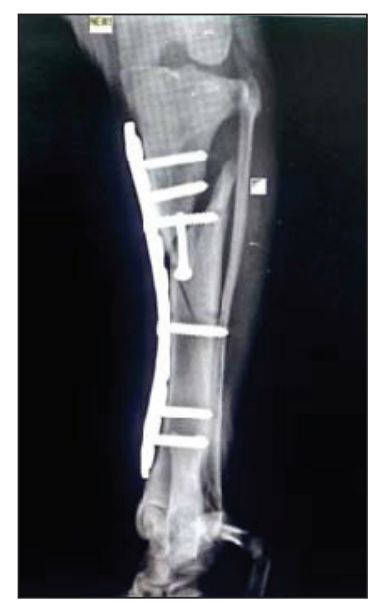

(b)

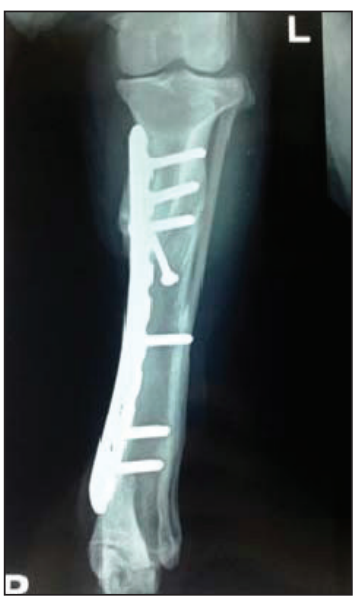

(c)

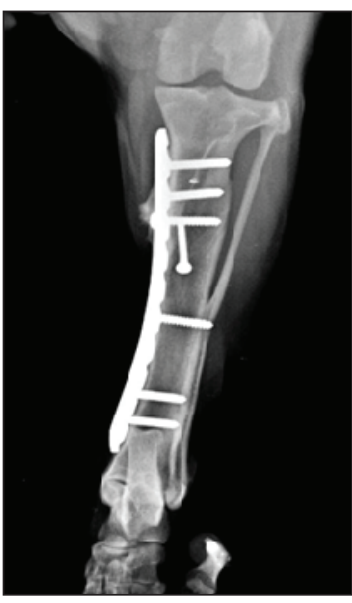

(d)

Fig. 6: Radiographs taken preoperatively (a), post-fracture fixation (b), $6^{\text {th }}$ (c) and $10^{\text {th }}(\mathbf{d})$ postoperative week showing stable fixation and primary bone healing of tibial fracture (Case 1)

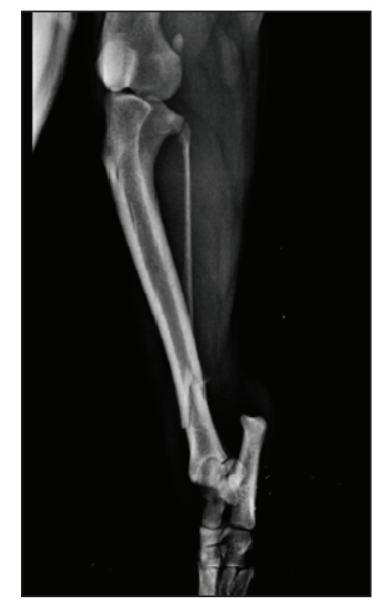

(a)

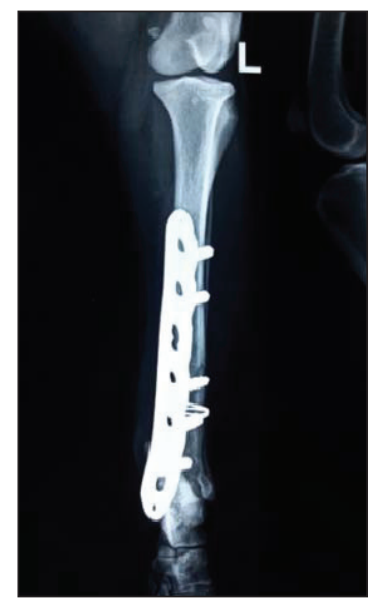

(b)

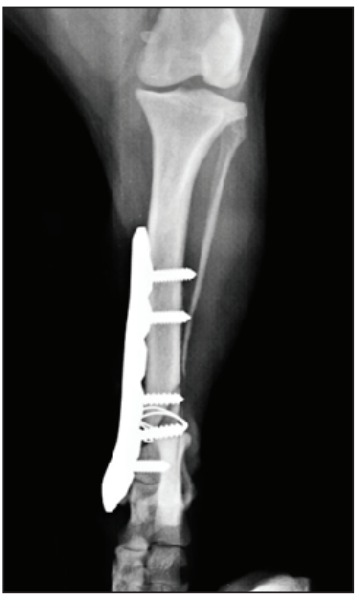

(c)

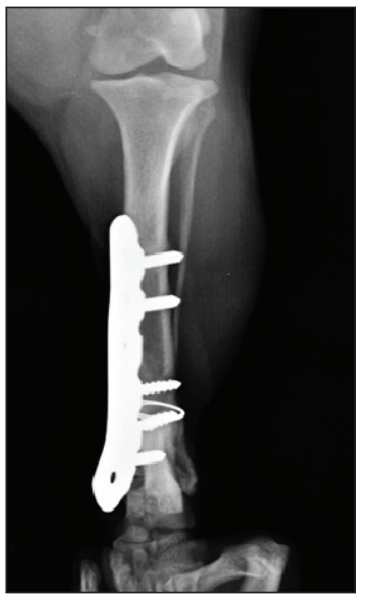

(d)

Fig. 7: Radiographs of tibia taken preoperatively (a), post-fracture fixation $(\mathbf{b}), 6^{\text {th }}(\mathbf{c})$ and $10^{\text {th }}(\mathbf{d})$ postoperative week showing stable fixation and primary bone healing (Case 2) 


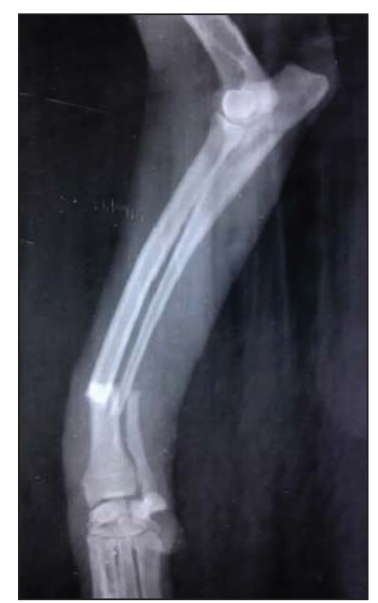

(a)

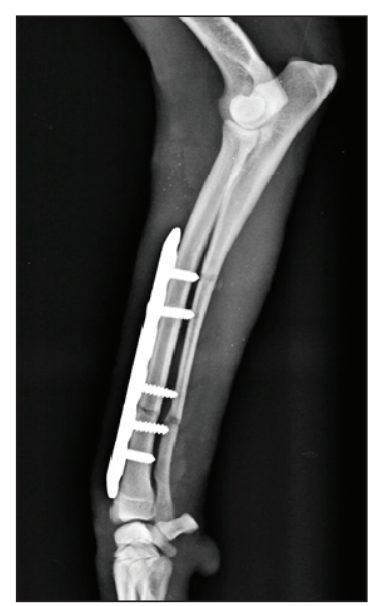

(b)

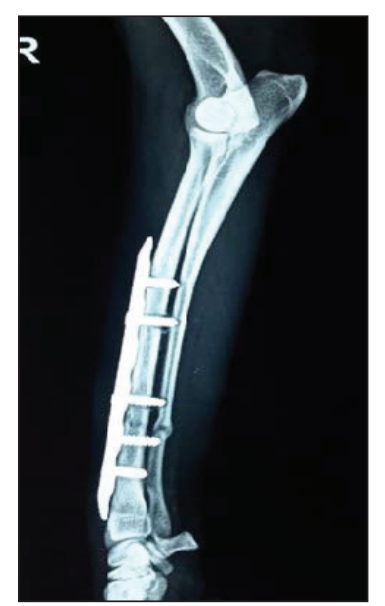

(c)

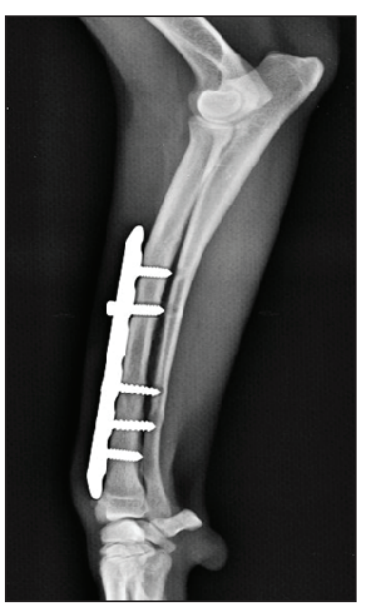

(d)

Fig. 8: Healing progress on a radiograph of radius ulna fracture taken preoperatively (a) immediate (b) 6 weeks and 10 week post surgery in case 9

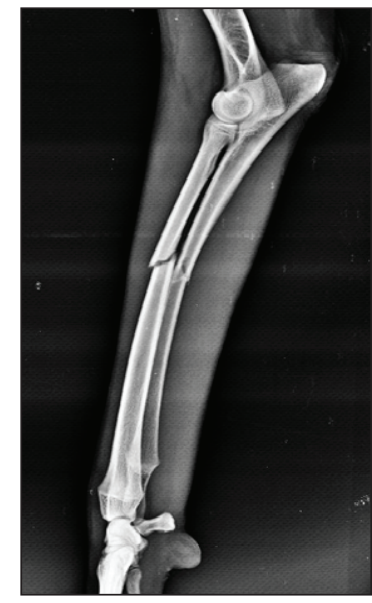

(a)

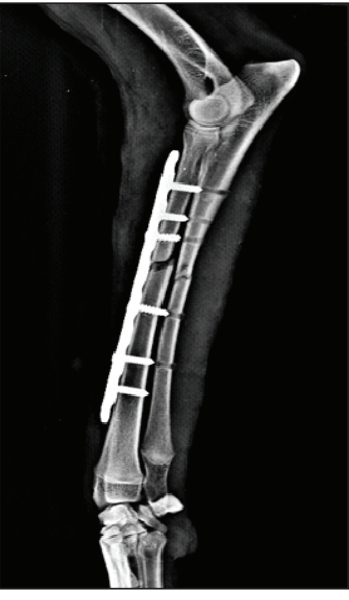

(b)

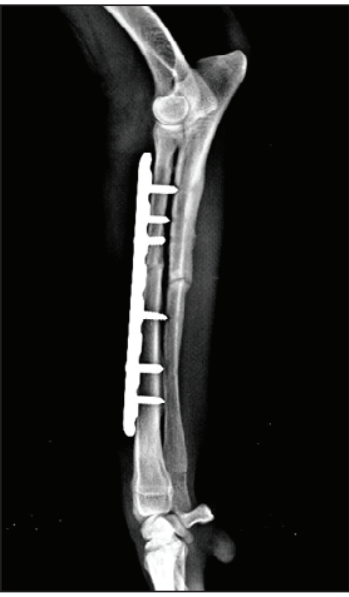

(c)

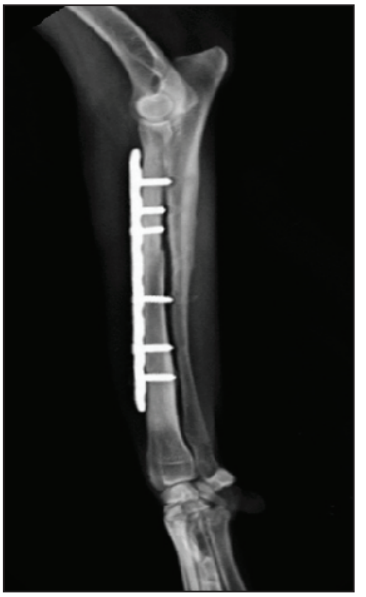

(d)

Fig. 9: Radiographs at preoperative (a), post-fracture fixation $(\mathbf{b}), 6^{\text {th }}(\mathbf{c})$ and $10^{\text {th }}(\mathbf{d})$ postoperative week showing stable fixation and primary bone healing at different intervals (Case 10)

healing in five cases, gap healing was seen in five with minimum callus whereas other two healed by callus formation. Hybrid locked plating allowed implant stability with inter-digitations of fragment ends; there was low strain at fracture ends and fractures healed with minimum callus formation (Beale, 2004). Radio-lucency observed at the fracture site on early healing days represented bone resorption by osteoclasts in order to reduce the interfragmentary strain which was followed by new bone formation and restoration of complete cortical continuity and obliteration of fracture line (Kallianpur et al., 2019). Loss of alignment due to uncontrolled movement post- fixation led to callus formation, lowering rigidity to fixation and loss of anatomical reduction (Sirin et al., 2013).

No major complications were recorded in our study, but minor complications such as seroma formation (Fig. 10A), external rotation of limb (Fig. 10B), wound dehiscence (Fig. 10A) and screw loosening were observed in some (Table 3). Outcome studies on locked plating in simple transverse and short oblique fractures had recorded complications such as fixation failure (Haaland et al., 2009; Kallianpur et al., 2019), plate and/or screw breakage (Kallianpur et al., 2018), osteomyelitis (Haaland 
et al., 2009) and atropic non-union (Sommer et al., 2004). Major complications could be avoided in our study due to selection of fractures suitable for fixation and appropriate screw configuration.

Table 3: Functional recovery and complications observed during the study period

\begin{tabular}{|c|c|c|c|}
\hline $\begin{array}{l}\text { Case } \\
\text { No. }\end{array}$ & $\begin{array}{l}\text { Functional } \\
\text { recovery }\end{array}$ & $\begin{array}{l}\text { Minor } \\
\text { complication }\end{array}$ & Client opinion \\
\hline 1 & Very good & - & Satisfied \\
\hline 2 & Very good & - & Satisfied \\
\hline 3 & Very good & - & Satisfied \\
\hline 4 & Good & - & $\begin{array}{l}\text { Satisfied after } \\
\text { weight bearing }\end{array}$ \\
\hline 5 & Very good & - & Satisfied \\
\hline 6 & Very good & - & Satisfied \\
\hline 7 & Good & $\begin{array}{l}\text { Wound } \\
\text { dehiscence, } \\
\text { persists for } 2 \\
\text { months (long } \\
\text { term) }\end{array}$ & $\begin{array}{l}\text { Satisfied after } \\
\text { complete wound } \\
\text { healing }\end{array}$ \\
\hline 8 & Very good & $\begin{array}{l}\text { LHS loosened } \\
\text { from second } \\
\text { proximal } \\
\text { locking hole } \\
\text { (long term) }\end{array}$ & Satisfied \\
\hline 9 & Very good & - & Satisfied \\
\hline 10 & Very good & - & Satisfied \\
\hline 11 & Very good & - & Satisfied \\
\hline 12 & Satisfactory & $\begin{array}{l}\text { Slight } \\
\text { angulation of } \\
\text { distal fragment } \\
\text { (carpus valgus) } \\
\text { (long term) }\end{array}$ & $\begin{array}{l}\text { Satisfied, but } \\
\text { worried about limb } \\
\text { deviation }\end{array}$ \\
\hline
\end{tabular}

Integration of locking and non locking screws into one implant allowing advantages of dynamic compression and locking head fixation, posed biomechanical advantage to selected fractures (Johnson, 2013). Purchase of locking screw on bone was difficult to be felt by surgeon, which led to under tightening or over tightening of screws (Sommer et al., 2004). In addition to this, locking hole did not allow screws to be angled more than $5^{\circ}$, hence mal-aligned screw led to screw loosening or migration (Boudrieau,
2018). These attributed to locking head screw loosening in one case. Seroma formation was more or less attributed to excessive limb movement during early post-operative days. Loss of anatomical alignment due to excess limb use led to external rotation in two cases; however, fixation was stable and fracture healed completely with callus formation. Initial angular deformities of up to $30^{\circ}$ in the sagittal plane and $20^{\circ}$ in the coronal plane could remodel into satisfactory alignment with external coaptation (Malkawi et al., 1986). Self-mutilation led to wound dehiscence in one case wherein uneventful recovery was observed with skin graft using SIS scaffold (Fig. 11A and 11B).

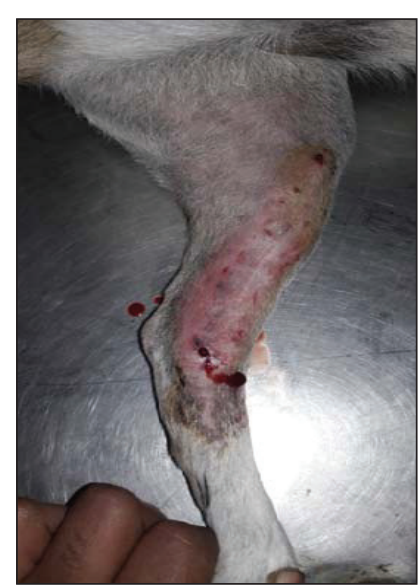

(a)

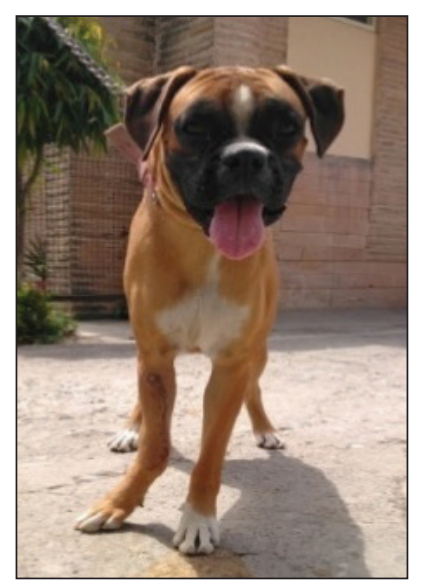

(b)
Fig. 10: Photograph showing seroma on $2^{\text {nd }}$ postoperative week in case 2 (a) and showing carpus valgus in case 12 (b) on $6^{\text {th }}$ postoperative weeks

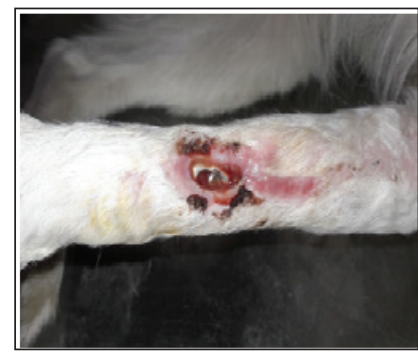

(a)

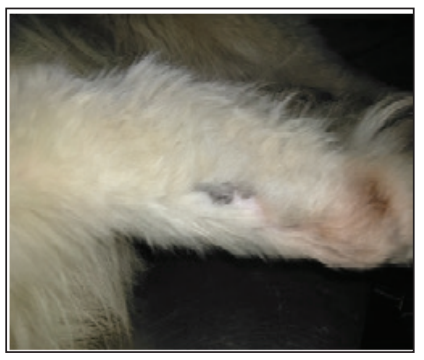

(b)
Fig. 11: Photographs showing wound dehiscence (a), and complete wound healing on $10^{\text {th }}$ post- operative week (b) in case 10

Functional recovery grade was 'Very good' in nine cases on 
$10^{\text {th }}$ postoperative week, 'Good' in two and 'Satisfactory' in one case (Table 3). Radiographic union and good limb function led to very good functional outcome in nine cases on $10^{\text {th }}$ postoperative week. Functional outcome also represented minimum intra-operative soft tissue damage with lower operative time and stable fixation provided by the hybrid locked plating. Commendable bone union was achieved with this technique with early limb usage and minor complications.

\section{CONCLUSION}

Findings of the present study allowed us to conclude that locking plate with hybrid screw configuration as in Hybrid locked plating could be a stable fixation technique, which provided inter-fragmentary compression while maintained vascular supply to fracture site to achieve radiographic primary bone healing and very good functional outcome for the management of transverse and short oblique diaphyseal tibial and radius-ulna fractures in dogs.

\section{ACKNOWLEDGEMENTS}

The authors acknowledge the scholars, scientific and technical staff of Division of Surgery and Teaching Veterinary Clinical Complex cum Referral Veterinary Polyclinic, and Director ICAR-Indian Veterinary Research Institute, Izzatnagar, Bareilly, Uttar Pradesh, India for providing necessary support and help at various level for the study.

\section{REFERENCES}

Aguila, A.Z., Manos, J.M., Orlansky, A.S., Todhunter, R.J., Trotter, E.J. and Van der Meulen, M.C.H. 2005. In vitro biomechanical comparison of limited contact dynamic compression plate and locking compression plate.

Au, B., Groundland, J., Stoops, T.K., Santoni, B.G., Sagi, H.C. 2017. Comparison of 3 methods for maintaining inter-fragmentary compression after fracture reduction and fixation. J. Orthop. Trauma., 31: 210-213.

Beale, B. 2004. Orthopedic clinical techniques femur fracture repair. Clin. Tech. Small Anim. Pract., 19(3): 134-150.

Bel, J.C. 2019. Pitfalls and limits of locking plates. Orthop. Traumatol. Surg. Res., 105: S103-S109.

Boudrieau, R. 2018. Complications specific to locking plates. In: Griffon DA, Hamaide, eds Complications in small animal surgery. Wiley-Blackwell, Ames, Iowa, pp: 714-724.
Cook, J.L., Tomlinson, J.L. and Reed, A.L. 1999. Fluoroscopically guided closed reduction and internal fixation of fractures of the lateral portion of the humeral condyle: prospective clinical study of the technique and results in ten dogs. Vet. Surg., 28(5): 315-321.

Cross, A.R., Budsberg, S.C. and Keefe, T.J. 1997. Kinetic gait analysis assessment of meloxicam efficacy in a sodiumurateinduced synovitis model in dogs. Am. J. Vet. Res., 58(6): 626631.

Dvorak, M., Neaas, A. and Zatloukal, J. 2000. Complications of long bone fracture healing in dogs: Functional and Radiological criteria for their assessment. Acta Vet. Brno., 69(2): 107-114.

Egol, K.A., Kubiak, E.N., Fulkerson, E., Kummer, F.J. and Koval, K.J. 2004. Biomechanics of locked plates and screws. J. Orthop. Trauma., 18(8): 488-493.

Gibert, S., Ragetly, G.R. and Boudrieau, R.J. 2015. Locking compression plate stabilization of 20 distal radial and ulnar fractures in toy and miniature breed dogs. Vet. Comp. Orthop. Traumatol., 28(6): 441-447.

Haaland, P.J., Sjostrom, L., Devor, M. and Haug, A. 2009. Appendicular fracture repair in dogs using the locking compression plate system: 47 cases. Vet. Comp. Orthop. Traumatol., 22(4): 309-315.

Johnson, A.L. 2013. Fundamentals of Orthopedic Surgery and Fracture Management 1033-1093. In: Fossum, T.W. ed. Small animal surgery. Edition IV. St. Louis, Missouri, Elsevier, Moseby 2013; pp. 1033-105.

Johnson, A.L., Seitz, S.E., Smith, C.W., Johnson, J.M. and Schaeffer, D.J. 1996. Closed reduction and type-II external fixation of comminuted fractures of the radius and tibia in dogs: 23 cases (1990-1994). J. Am. Vet. Med. Assoc., 209(8): 1445-1448

Kallianpur, N., Singh, K., Gopinathan, A., Sarangom, S.B., John, C., Sowbharenya, C. and Sharma, P. 2018. Investigation on relationship between factors affecting occurrence and outcome of repair of long bone fractures in 216 dogs. Int. J. Livest. Res., 8(2): 225-234.

Kallianpur, N., Singh, K., Gopinathan, A., Sarangom, S.B., Sharma, P., Sowbharenya, C. and John, C. 2019. Preliminary investigation on effects of two different cortical-screw configuration on locking plates for the repair of simple diaphyseal long bone fractures in dogs. J. Anim. Plant Sci., 29(3): 427-447.

Kumar, P. 2007. Studies on the occurrence and management of compound fracture using epoxy pin/metallic linear and circular external skeletal fixation devices in animals. MVSc thesis, ICAR-Indian Veterinary Research Institute, Izatnagar, India. 
Leung, F. and Chow, S.P. 2006. Locking compression plate in the treatment of forearm fractures: a prospective study. $J$. Orthop. Surg., 14(3): 291-294.

Malkawi, H., Shannak, A. and Hadidi, S. 1986. Remodeling after femoral shaft fractures in children treated by the modified blount method. J. Pediatr. Orthop., 6(4): 421-429.

Moses, P.A., Lewis, D.D., Lanz, O.I., Stubbs, W.P. and Cross, A.R. 2002. Intramedullary interlocking nail stabilization of 21 humeral fractures in 19 dogs and one cat. Aust. Vet. J., 80(6): 336-343.

Namazi, H. and Mozaffarian, K. 2007. Awful considerations with LCP instrumentation: a new pitfall. Arch. Orthop. Trauma Surg., 127(7): 573-575.

Niemeyer, P. and Sudkamp, N.P. 2006. Principles and clinical application of the locking compression plate (LCP). Acta. Chir Orthop. Traumatol. Cech., 73(4): 221-228.

Perren, S.M. 2002. Evolution of the internal fixation of long bone fractures. J. Bone Jt. Surg., 84(8): 1093-1110.

Ramesh, R. 2011. Locking Plate System for the management of unstable diaphyseal, metaphyseal fractures of femur, humerus and radius in dogs. Ph.D. Thesis, Tamil Nadu Veterinary and Animal Sciences University, Chennai (TN), India 2011.

Reems, M.R., Beale, B.S. and Hulse, D.A. 2003. Use of a platerod construct and principles of biological osteosynthesis for repair of diaphyseal fractures in dogs and cats: 47 cases (1994-2001). J. Am. Vet. Med. Assoc., 223(3): 330-335.

Scolaro, J. and Ahn, J. 2011. Locked plating in practice:
Indications and current concepts. UPOJ, 21: 18-22.

Singh, A.P., Mirakhur, K.K. and Nigam, J.M. 1983. A study on the incidence and anatomical locations of fractures in canines, caprine, bovine, equine and camel. Indian J. Vet. Surg., 4: 61-66.

Sirin, O.S., Sirin, Y.S. and Yigitarslan, K. 2018. Uni-LOCK implants for stabilization of long bone fractures: Experiences in ten clinical cases. Ank. Univ. Vet. Fak. Derg., 65(2): 179185

Sirin, S.O., Kaya, U. and Olcay, B. 2013. Clinical and radiological outcomes of Locking Compression Plate System in dogs with diaphyseal fractures: 32 Cases. Kafkas. Univ. Vet. Fak. Derg., 19 (Suppl A): 13-18.

Sommer, C., Babst, R., Müller, M. and Hansom, B. 2004. Locking compression plate loosening and plate breakage: a report of four cases. J. Orthop. Trauma., 18(8): 571-577.

Sommer, C., Schuetz, M. and Wagner, M. 2007. Internal Fixator. In: Ruedi TP, Buckley RE, Moran, CG eds. AO Principles of Fracture Management. Thieme, pp. 320-335.

Thilagar, S. and Balasubramanian, N.N. 1988. A retrospective study on the incidence and anatomical locations in 204 cases of fracture in dogs. Cherion, 17(2): 68-71. 
